\title{
VARIABILIDADE GENÉTICA EM CARACTERES MORFOLÓGICOS, AGRONÔMICOS E CITOGENÉTICOS DE POPULAÇÕES DE MARACUJAZEIRO-DOCE (Passiflora alata Curtis) ${ }^{1}$
}

\author{
LAURA MARIA MOLINA MELETTI ${ }^{2}$, LUIS CARLOS BERNACCI ${ }^{2}$, MARTA DIAS SOARES-SCOTT ${ }^{2}$, JOAQUIM \\ ADELINO DE AZEVEDO FILHO ${ }^{3}$, ANTONIO LÚCIO MELLO MARTINS ${ }^{3}$
}

\begin{abstract}
RESUMO - O maracujazeiro-doce (Passiflora alata Curtis) é uma espécie polimorfa, com significativas variações quanto ao tamanho e formato dos frutos, peso, espessura da casca, coloração de polpa e número de sementes por fruto. A propagação por sementes predomina e amplia a variabilidade entre as plantas cultivadas. Foi feita a caracterização morfológica, agronômica e citogenética dos acessos Mogi-Guaçu, Grande, Jaboticabal, OuroMiúdo, Campinas, Gomo e CENARGEN. Os acessos 'Mogi-Guaçu' e 'Grande' foram superiores na maioria das características avaliadas. Termos para indexação: maracujá-doce, $P$. alata, variabilidade, caracterização.

\section{GENETIC VARIABILITY OF MORPHOLOGICAL, AGRONOMIC AND CYTOGENETICS CHARACTERS OF SWEET PASSION-FRUIT POPULATIONS (Passiflora alata Curtis)}

\begin{abstract}
The sweet passion fruit (Passiflora alata Curtis) is polymorphic with high variability in size, shape, weight, thickness of cortex, color of pulp and number of seeds in the fruit. The propagation by seeds increases the heterosis of the cultivated plants. The aim of this paper was to evaluate agronomic, morphological and cytogenetics aspects and identify native population of passion fruit. The introductions Mogi-Guaçu and Grande showed better characteristics.
\end{abstract}

Index terms: sweet passion-fruit, Passiflora alata, variability, caracterization.

\section{INTRODUÇÃO}

O maracujazeiro-doce (Passiflora alata Curtis - Bernacci et al., 2003) é uma espécie brasileira, encontrada no Pará e do Centro-Oeste e Bahia até o Rio Grande do Sul, mas ainda é desconhecida da maioria da população. O cultivo comercial tem se expandido em função dos elevados preços do produto no mercado de frutas frescas (Vasconcellos \& Cereda, 1994). Aindústria farmacêutica também utiliza a passiflorina, um calmante natural extraído das folhas, para fins medicinais (Meletti \& Maia, 1999). É uma espécie adequada para caramanchões e cercas-vivas, de crescimento vigoroso, cujo valor ornamental se distingue pelas flores vistosas, coloridas e perfumadas.

Na agroindústria, $P$. alata não é utilizada como matéria-prima fornecedora de frutos, devido à sua polpa excessivamente adocicada, que produz um suco de sabor enjoativo (Oliveira et al., 1982). Mas a espécie é considerada tolerante a moléstias de solo, e por isso poderá vir a ser utilizada como porta-enxerto para as cultivares de maracujazeiroamarelo, embora esta enxertia ainda não seja comercialmente utilizada.

Importantes iniciativas de expansão da cultura têm sido observadas, devido à significativa elevação dos preços no CEAGESP e interior paulista, onde ele é mais conhecido. No mercado varejista, é vendido a preços muito superiores aos praticados para o maracujá-amarelo, o que tem atraído os produtores. Apesar do contexto altamente favorável, faltam informações técnicas que permitam um manejo adequado dos pomares e do fruto.

Produtores mais tecnificados têm selecionado matrizes superiores em produtividade e qualidade, propagando-as por estaquia, para manter suas características (Meletti \& Maia, 1999). O maracujazeiro é uma planta de fecundação cruzada por excelência, por apresentar elevada taxa de auto-incompatibilidade, também observada em $P$. alata (Vasconcellos et al., 2001). Isto resulta na perda de identidade genética e amplia a variabilidade dos pomares. A estaquia supera estas limitações, mas exige a disponibilidade de vários clones selecionados e compatíveis entre si, que, recombinados, resultarão em frutos superiores. A maioria dos produtores, no entanto, não têm acesso a essas matrizes.

A inexistência de cultivares comerciais dificulta ainda mais a obtenção de material de propagação selecionado, e por isso as mudas resultam de sementes sem seleção, retiradas de frutos do comércio varejista, aumentando também a variabilidade das plantas. Oliveira et al. (1982) observaram que o polimorfismo do maracujazeiro-doce resulta em significativas variações no tamanho e formato dos frutos, peso, espessura da casca, coloração e porcentagem de polpa e número de sementes.

A heterogeneidade dos frutos também se traduz em preços diferenciados no mercado. Segundo Vasconcellos et al. (2001), as caixetas de comercialização, com cerca de $3,5 \mathrm{~kg}$, recebem a classificação por tipo $(10 ; 12 ; 15 ; 18 ; 21$ ou 24$)$, de acordo com a quantidade de frutos que nelas cabem. As caixetas tipo 10 ou 12 são cotadas a preços consideravelmente superiores ao da caixeta tipo 15, e assim sucessivamente.

Considerando ainda a curta viabilidade das sementes (Vasconcellos et al., 2001), que leva a uma semeadura quase imediata à retirada dos frutos, mais a auto-incompatibilidade presente na espécie, novos pomares poderiam ser formados a partir de uma mistura de um número significativo de clones, altamente produtivos, com qualidade de fruto e mais tolerantes a moléstias. Esses clones formariam um conjunto de matrizes selecionadas, mantidas por enraizamento de estacas ou cruzamento manual controlado. Isto poderia contribuir para a obtenção de lavouras muito superiores às atuais (Ruggiero, 1991; Meletti \& Maia, 1999).

A avaliação de populações nativas e comerciais de Passiflora alata permite a seleção de clones. Para tanto, faz-se necessária a identificação de acessos mais produtivos, mais adaptados às diferentes regiões de cultivo e/ou com características comercialmente desejáveis. Estes estudos ampliam o conhecimento da base genética disponível e fundamentam o melhoramento genético da espécie.

Assim, o objetivo deste trabalho foi avaliar diferentes populações de Passiflora alata do Banco Ativo de Germoplasma (BAGs) do IAC, caracterizando-as morfológica, agronômica e citogeneticamente, a fim de identificar indivíduos superiores, de alta fertilidade, visando à seleção de clones mais produtivos e homogêneos.

\section{MATERIALEMÉTODOS}

O experimento foi conduzido nos BAGs das Estações Experimentais do Departamento de Desenvolvimento Descentralizado (DDD)APTA, localizadas em Jundiaí (1992-1995), Pindorama (1995-1997) e Monte Alegre do Sul (1997-2002), SP. Foram estudados os acessos (com indicação do número de registro do material-testemunha no herbário IAC) 'Campinas' (IAC 37970), 'CENARGEN' (IAC 31087), 'Grande' (IAC 42850), 'Jaboticabal' (IAC 37156), 'Mogi-Guaçu' (IAC 37465), e 'Ouro-Miúdo' (IAC 42851).

As matrizes foram obtidas a partir de sementes, coletadas em

\footnotetext{
${ }^{1}$ (Trabalho 188/2002).Recebido: 13/12/2002. Aceito para publicação: 18/07/2003. Realizado com apoio financeiro da FUNDAG.

${ }^{2}$ Pesq. Científico, Instituto Agronômico de Campinas, Cx. Postal 28 - CEP:13.001-970. Campinas, SP; 1mmm @iac.br. F: (19) 3241-9910.

${ }^{3}$ Pesq. Científico, APTA, Departamento de Desenvolvimento Descentralizado
} 
pomares comercias de São Paulo e Minas Gerais, em outros BAGs brasileiros e em expedições de coleta. As plantas foram formadas e conduzidas segundo as recomendações técnicas para a cultura no Estado de São Paulo (Meletti \& Maia, 1999), e avaliadas por duas safras consecutivas, seqüenciais e não concomitantes, nas diferentes localidades. Fez-se a caracterização agronômica, morfológica e citogenética, analisando-se populações distribuídas em blocos ao acaso, com 5 repetições e 3 plantas por parcela em Pindorama; em blocos ao acaso, com 3 repetições e 3 plantas por parcela em Jundiaí e em delineamento inteiramente casualizado, com 3 plantas por parcela, em Monte Alegre do Sul, onde havia maior homogeneidade na área experimental.

A caracterização agronômica foi feita com base nas seguintes características: velocidade de crescimento; número médio de flores por planta, em dois picos de florescimento; peso médio dos frutos; comprimento e diâmetro equatorial dos frutos $(\mathrm{cm})$; número de sementes por fruto; espessura do mesocarpo $(\mathrm{cm})$ e teor de sólidos solúveis totais ( ${ }^{\circ}$ Brix). Avaliou-se, também, o efeito da época do ano e sua precipitação pluviométrica sobre o teor de SST ( ${ }^{\circ}$ Brix) dos frutos coletados em Monte Alegre do Sul, durante as safras de 1997 a 2002. A velocidade de crescimento foi estimada pela altura das plantas aos 100 dias após plantio e pelo diâmetro do caule na fase vegetativa, medido na região de bifurcação do ramo primário em dois secundários, a $2 \mathrm{~m}$ do solo. Para a análise dos frutos, considerou-se uma amostra de 15 frutos por acesso, tomados ao longo da safra de cada ano agrícola.

Para a caracterização morfológica, foram considerados: comprimento e largura da lâmina foliar e da estípula, e comprimento do pecíolo e do apículo foliar; entre as características vegetativas; comprimento e largura da bráctea, sépala e pétala, e comprimento do pedúnculo, pedicelo, hipanto e arista da sépala, entre as características florais, tendo sido estudados os acessos 'Jaboticabal', 'Mogi-Guaçu', 'Grande' e 'OuroMiúdo'. Estes acessos foram comparados, conjuntamente, e acesso a acesso, com um conjunto de plantas nativas do Estado de São Paulo, listadas por Bernacci et al. (2002), através da análise de quartis ("box plots"), segundo McGill et al. (1978).

Para a análise citogenética, foram coletadas pontas de raiz e botões florais, pré-tratados com 8-hidroxiquinolina a $0,03 \%(0,002 \mathrm{M})$ por 3 horas, à temperatura ambiente, em seguida fixados em etanol acético (3:1) e mantidos a $7^{\circ} \mathrm{C}$. O cariótipo foi montado a partir de 10 metáfases, segundo Levan et al. (1964). A análise de viabilidade polínica foi realizada de acordo com Alexander (1980), a partir de flores em antese. Foram contados 300 grãos de pólen por flor e 10 flores por acesso, coletadas em diferentes meses do ano.

\section{RESULTADOS E DISCUSSÃO}

Os dados de avaliação agronômica e de viabilidade polínica das populações de maracujazeiro-doce encontram-se na Tabela 1 . O efeito de blocos nas avaliações de Pindorama e Jundiaí não foi significativo, motivo pelo qual os dados apresentados na Tabela 1 consideram a média das 3 localidades, tendo sido observada a mesma significância esta- tística na distribuição das médias, independentemente do local, para todas as características avaliadas.

Durante a fase vegetativa, os acessos 'Mogi-Guaçu' e 'Grande' foram os mais vigorosos, por terem apresentado a maior velocidade de crescimento, ou seja, a maior altura de planta aos 100 dias, e o maior diâmetro de caule na altura da bifurcação. Isto resultou na antecipação da produção, uma vez que eles floresceram de 25 a 35 dias antes dos outros, principalmente nos anos mais quentes. O número médio de flores por planta, em pico de florescimento, também se apresentou na classe superior para eles, assim como para os acessos 'Jaboticabal' e OuroMiúdo. No entanto, considerando o número de flores, a viabilidade polínica e o peso dos frutos resultantes, observa-se a superioridade de 'Mogi-Guaçu' e 'Grande', com viabilidade de pólen acima de 84\%, e frutos maiores e mais pesados que 'Jaboticabal' e 'Ouro-Miúdo'.

Em relação ao peso do fruto, comprimento e diâmetro equatorial, os resultados encontrados para os acessos 'Mogi-Guaçu' e 'Grande' superam os obtidos por Veras (1997), que foram de 197,4g, 10,47cm e $7,06 \mathrm{~cm}$, respectivamente, demonstrando que os frutos ora avaliados, maiores e mais pesados, representam seleções com características comerciais altamente desejáveis.

Conforme observado por Meletti et al. (1994), há uma relação direta entre a alta viabilidade polínica e o elevado número de sementes por fruto, novamente constatada no presente experimento (Tabela 1). Quando associada à polinização manual, os mesmos acessos ('MogiGuaçu'e 'Grande') mostraram superioridade para estas características.

Não houve diferença significativa entre os teores de SST das populações estudadas, considerando as médias obtidas nas três localidades(Tabela 1). Todas superaram aquela observada por Veras (1997), que foi de $18,4^{\circ}$ Brix para a espécie, alcançando valores de 19,8 a $22,8^{\circ}$ Brix, conforme o acesso. No entanto, quando avaliada sob influência da precipitação pluviométrica, em Monte Alegre do Sul, esta característica foi nitidamente influenciada pela época do ano (Tabela 2). No período mais chuvoso (dezembro a março), as médias obtidas foram significativamente inferiores às do período mais seco (maio a julho), demonstrando que a precipitação pluviométrica reduziu o teor de SST dos frutos, independentemente do genótipo considerado. Isto foi confirmado pelo coeficiente de correlação obtido $\left(R^{2}=-0,90\right)$. Para este parâmetro, portanto, observou-se uma relação inversamente proporcional à pluviosidade, ou seja, quanto mais chuva, menor o teor de SST $\left({ }^{\circ}\right.$ Brix $)$ dos frutos.

Quanto à espessura de casca, 'Mogi-Guaçu' apresentou média equivalente ao observado por Veras (1997). Todos os outros apresentaram casca mais fina, o que representa menos descarte para o consumidor, mas também menor resistência mecânica ao transporte e manuseio. Há necessidade de desenvolver-se um padrão para esta característica, ainda inexistente, aliando uma cavidade interna maior com rendimento em polpa, sem que isto signifique maior dano físico ao fruto, devido à baixa resistência do mesocarpo.

Os acessos 'Mogi-Guaçu' e 'Grande' foram superiores aos demais, considerando-se as diferentes características agronômicas avaliadas.

TABELA 1 - Médias de características agronômicas e Viabilidade Polínica (VP) de Maracujazeiro-doce (Passiflora alata Curtis), 1992-2002. Instituto Agronômico, Jundiaí, Pindorama e Monte Alegre do Sul-SP.

\begin{tabular}{|c|c|c|c|c|c|c|c|c|c|c|}
\hline & \multicolumn{2}{|c|}{ VEGETATIVO } & \multicolumn{2}{|c|}{ FLORES } & \multicolumn{6}{|c|}{ FRUTOS } \\
\hline $\begin{array}{c}\text { Acesso BAG } \\
\text { Passiflora alata }\end{array}$ & $\begin{array}{c}\text { Altura } 100 \\
\text { dias } \\
(\mathrm{cm})\end{array}$ & $\begin{array}{l}\varnothing \mathrm{BIF} \\
\text { caule } \\
(\mathrm{cm})\end{array}$ & $\begin{array}{l}\text { Num.m } \\
\text { Flores } \\
\text { planta* }\end{array}$ & $\begin{array}{l}\text { VP } \\
(\%)\end{array}$ & $\begin{array}{l}\text { Peso fruto } \\
\text { (g) }\end{array}$ & $\begin{array}{l}\text { Compr. } \\
\text { fruto }(\mathrm{cm})\end{array}$ & $\begin{array}{c}\varnothing . \text { Equat. } \\
\text { fruto } \\
(\mathrm{cm})\end{array}$ & $\begin{array}{c}\text { Esp. } \\
\text { mesoc. } \\
(\mathrm{cm})\end{array}$ & $\begin{array}{c}\text { Teor } \\
\text { SST } \\
\left({ }^{\circ} \text { Brix }\right)\end{array}$ & $\begin{array}{l}\text { Num.m. } \\
\text { Semente } \\
\text { fruto }\end{array}$ \\
\hline Mogi-Guaçu & $1,78 \mathrm{a}$ & $1,9 \mathrm{a}$ & $15 \mathrm{ab}$ & 89,8 & $342 \mathrm{a}$ & $13,9 \mathrm{a}$ & $8,5 \mathrm{a}$ & $1,13 \mathrm{a}$ & $22,2 \mathrm{~ns}$ & $312 \mathrm{a}$ \\
\hline Grande & $1,53 \mathrm{a}$ & $1,8 \mathrm{a}$ & $18 \mathrm{a}$ & 84,8 & $272 \mathrm{a}$ & $11,2 \mathrm{~b}$ & $8,9 \mathrm{a}$ & $0,97 \mathrm{a}$ & $21,4 \mathrm{~ns}$ & $313 \mathrm{a}$ \\
\hline Jaboticabal & $1,40 \mathrm{~b}$ & $1,8 \mathrm{a}$ & $16 \mathrm{a}$ & 79,7 & $201 \mathrm{~b}$ & $9,3 \mathrm{~b}$ & $8,0 \mathrm{a}$ & $0,82 \mathrm{~b}$ & $20,8 \mathrm{~ns}$ & $279 \mathrm{a}$ \\
\hline Ouro-Miúdo & $1,33 \mathrm{~b}$ & $1,2 \mathrm{~b}$ & $19 \mathrm{a}$ & 77,8 & $177 \mathrm{c}$ & $8,8 \mathrm{bc}$ & $7,2 \mathrm{~b}$ & $0,77 \mathrm{~b}$ & $22,4 \mathrm{~ns}$ & $255 \mathrm{~b}$ \\
\hline Campinas & $1,08 \mathrm{bc}$ & $1,0 \mathrm{~b}$ & $10 \mathrm{c}$ & 72,9 & $159 \mathrm{c}$ & $8,2 \mathrm{c}$ & $6,9 \mathrm{~b}$ & $0,71 \mathrm{~b}$ & $22,0 \mathrm{~ns}$ & $172 \mathrm{c}$ \\
\hline Gomo & $0,98 \mathrm{c}$ & $0,9 \mathrm{~b}$ & $9 \mathrm{c}$ & & $151 \mathrm{c}$ & $8,0 \mathrm{c}$ & $7,1 \mathrm{~b}$ & $0,82 \mathrm{~b}$ & $19,8 \mathrm{~ns}$ & $186 \mathrm{c}$ \\
\hline CENARGEN & $0,97 \mathrm{c}$ & $0,9 \mathrm{~b}$ & $11 \mathrm{c}$ & 75,8 & $170 \mathrm{c}$ & $7,8 \mathrm{c}$ & $7,2 \mathrm{~b}$ & $0,79 \mathrm{~b}$ & $22,8 \mathrm{~ns}$ & $178 \mathrm{c}$ \\
\hline
\end{tabular}

* Média de dois picos de florescimento. Onde: $\varnothing \mathbf{B I F}=$ diâmetro na altura bifurcação; num.m= número médio; $\mathbf{V P}=$ viabilidade polínica; compr.= comprimento, $\varnothing$ equat $=$ diâmetro equatorial, esp. mesoc. $=$ espessura do mesocarpo; $\mathbf{S S T}=$ sólidos solúveis totais; $n$ s= diferença entre médias estatisticamente não significativa, pelo teste de Tukey, ao nível de 5\% de probabilidade. 
TABELA 2 - Teores médios de sólidos solúveis totais (SST) dos frutos de maracujazeiro-doce, em função da época do ano e média de precipitação mensal (mm). Monte Alegre do Sul, safras 1997 a 2002.

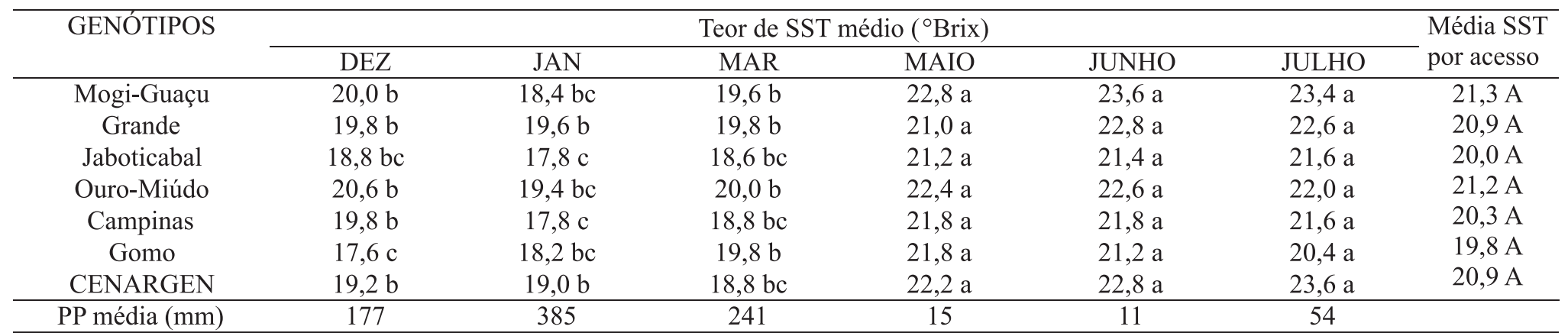

Onde: Médias seguidas pela mesma letra minúscula nas linhas não diferem entre si, pelo Teste de Tukey, ao nível de 5\% de probabilidade. Médias seguidas pela mesma letra maiúscula na coluna não diferem entre si, ao nível de 5\% de probabilidade.

Todas as populações analisadas de Passiflora alata floresceram de maio a novembro, nas diferentes localidades, com antese a partir das $7 \mathrm{~h} 30 \mathrm{~min}$, cujas flores permaneceram abertas até a noite. Picos de viabilidade de pólen foram observados em maio e junho, com média de $80,13 \%$, o que representa elevado potencial para produção de frutos e de sementes.

Quanto à tolerância às moléstias, todas as plantas mostraramse suscetíveis à bacteriose causada por Xanthomonas axonopodis pv. passiflorae Gonçalves \& Rosato 2000, sendo que 'Gomo' e 'Ouro-Miúdo' chegaram a morrer por ação deste patógeno. As demais apresentaram sintomas característicos, recuperando-se após controle curativo.

O número cromossômico de Passiflora alata é de $2 \mathrm{n}=18 \mathrm{Na}$ caracterização citogenética, não foram observadas diferenças cromossômicas entre os acessos, possivelmente por serem todos da mesma espécie. O cariótipo mostrou dois pares de cromossomos submetacêntricos ( 1 e 6 ), e dois pares portadores de satélite (4 e 7), sendo sua fórmula cariotípica $2 \mathrm{n}=7 \mathrm{M}+2 \mathrm{SM}$, indicando simetria cariotípica. A caracterização cromossômica da espécie está sendo apresentada (Tabela 3) pela primeira vez, sendo que, na literatura, constava, até então, apenas o número cromossômico (Soares-Scott, 1998).

TABELA 3 -Caracterização citogenética de $P$. alata: medidas cromossômicas obtidas numa média de 10 células. IAC, Campinas-SP, 2000.

\begin{tabular}{ccccc}
\hline Cromossomos & $\begin{array}{c}\text { Compr. } \\
\text { Absoluto }(\mu \mathrm{m})\end{array}$ & $\begin{array}{c}\text { Compr. } \\
\text { Relativo }(\mu \mathrm{m})\end{array}$ & $\begin{array}{c}\text { Razão de } \\
\text { braços }\end{array}$ & Tipo \\
\hline 1 & $2.99 \pm 0.18$ & $13.37 \pm 0.41$ & $1.74 \pm 0.12$ & $\mathrm{SM}$ \\
\hline 2 & $3.03 \pm 0.24$ & $13.46 \pm 0.44$ & $1.12 \pm 0.07$ & $\mathrm{M}$ \\
\hline 3 & $2.64 \pm 0.19$ & $11.78 \pm 0.51$ & $1.39 \pm 0.08$ & $\mathrm{M}$ \\
\hline 4 & $2.85 \pm 0.21$ & $12.68 \pm 0.31$ & $1.52 \pm 0.14$ & $\mathrm{M}$ \\
\hline 5 & $2.42 \pm 0.17$ & $10.76 \pm 0.18$ & $1.36 \pm 0.09$ & $\mathrm{M}$ \\
\hline 6 & $2.29 \pm 0.14$ & $10.22 \pm 0.38$ & $1.78 \pm 0.06$ & $\mathrm{SM}$ \\
\hline 7 & $2.68 \pm 0.16$ & $10.19 \pm 0.33$ & $1.09 \pm 0.21$ & $\mathrm{M}$ \\
\hline 8 & $2.00 \pm 0.13$ & $9.02 \pm 0.47$ & $1.24 \pm 0.06$ & $\mathrm{M}$ \\
\hline 9 & $1.98 \pm 0.14$ & $8.88 \pm 0.43$ & $1.08 \pm 0.05$ & $\mathrm{M}$ \\
\hline
\end{tabular}

Onde: $\mathrm{SM}=$ submetacêntrico; $\mathrm{M}=$ metacêntrico e compr. = comprimento.

O comprimento haplóide do genoma foi de $22.88 \mu \mathrm{m}$, próximo ao observado em outras espécies do gênero, sendo os cromossomos maiores os de número 1 , com centrômero na região submediana, e o de número 2, com centrômero na posição mediana, e os menores os de número 8 e 9, metacêntricos. Entretanto, observou-se, para o cromossomo 9, um comprimento absoluto de $1.98 \mu \mathrm{m}$, relativamente maior quando comparado às outras espécies do gênero Passiflora.

Pela caracterização morfológica, observou-se que os tamanhos das estruturas avaliadas nas populações cultivadas eram maiores que as dos acessos nativos, em vários caracteres, tanto vegetativos, tais como ramos (Figura 1a) e folhas (Figura 1b), quanto reprodutivos, tais como comprimento da pétala (Figura 1c) e largura da bráctea (Figura 1d).

A maioria dos acessos cultivados apresentou diferenças significativas em relação às plantas nativas, tal como em relação ao compri- mento e largura das folhas, onde 'Grande' e ‘Ouro-Miúdo' apresentaram os maiores comprimentos (Figura 2a) e larguras foliares (Figura 2b), não diferindo significativamente entre si, seguidos por 'Mogi-Guaçu' e 'Jaboticabal', este último sem diferenças significativas em relação aos acessos nativos.
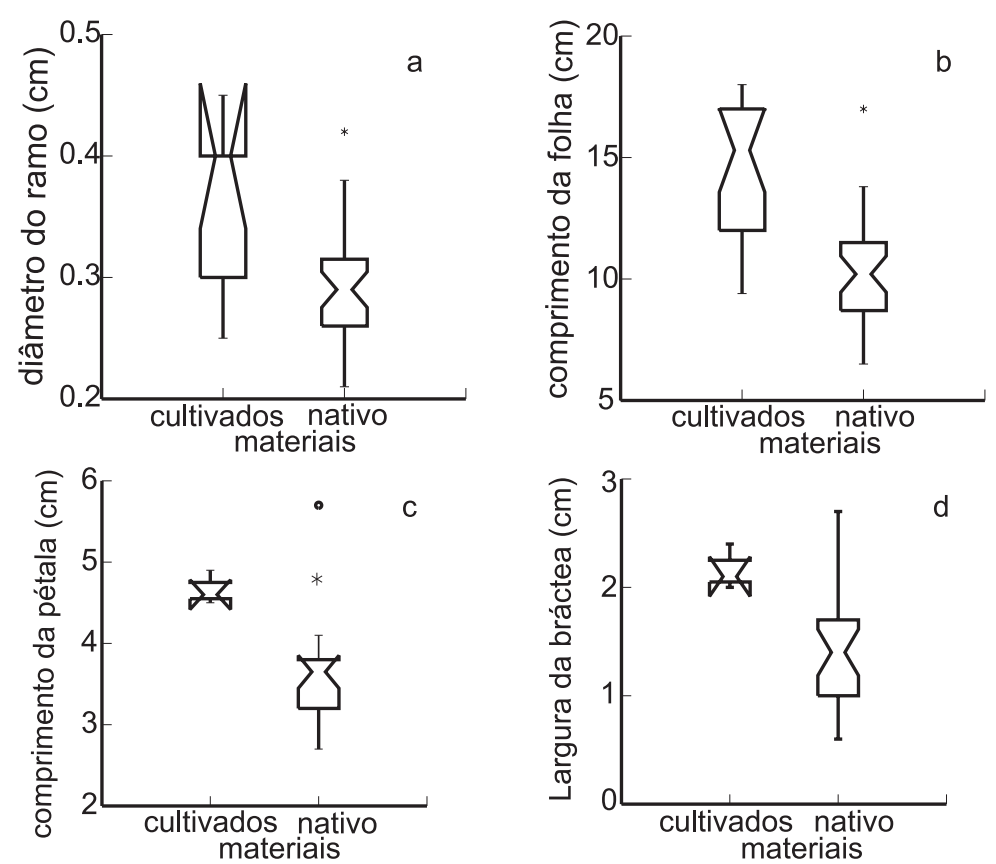

FIGURA 1 - Comparação entre diâmetro do ramo (a), comprimento da folha (b) e da pétala (c) e largura da bráctea $(\mathbf{d})$ de acessos de $P$. alata cultivados em Monte Alegre do Sul e plantas nativas do Estado de São Paulo. Diferenças significativas se estreitamento no polígono não sobrepostos.

Quando não existiam diferenças significativas entre o conjunto de acessos cultivados e o das plantas nativas (Figura 2c e 2e), um ou dois acessos apresentaram diferenças isoladamente, tal como 'Moji-Guaçu' em relação à largura da estípula (Figura 2d), maior que os demais, e 'Grande' e 'Moji-Guaçu, maiores em relação ao comprimento do pecíolo (Figura 2f).

A população dos acessos cultivados, com estruturas morfológicas maiores que as dos acessos nativos, provavelmente, foi alvo de algum tipo de seleção, realizada pelos produtores, uma vez que não existe cultivar definido. A escolha de plantas vigorosas, mais produtivas e com frutos de melhor qualidade, pode ter resultado na seleção indireta para outras estruturas.

Entre os extremos de variação observados, destaca-se a largura da lâmina foliar, que chegou a atingir $13,8 \mathrm{~cm}$ no acesso 'Ouro-Miúdo'. Embora Salomão \& Andrade (1987) tenham registrado uma largura máxima de $16,7 \mathrm{~cm}$ para esta característica, afirmaram que a planta analisada podia tratar-se de um híbrido. O valor máximo registrado para o acesso 'Ouro-Miúdo' excede aqueles relatados por Killip (1938), Cervi (1997) e Bernacci et al. (2002), que estudaram diferentes populações nativas e apresentam descrições pormenorizadas das espécies. A seleção por plan- 
a
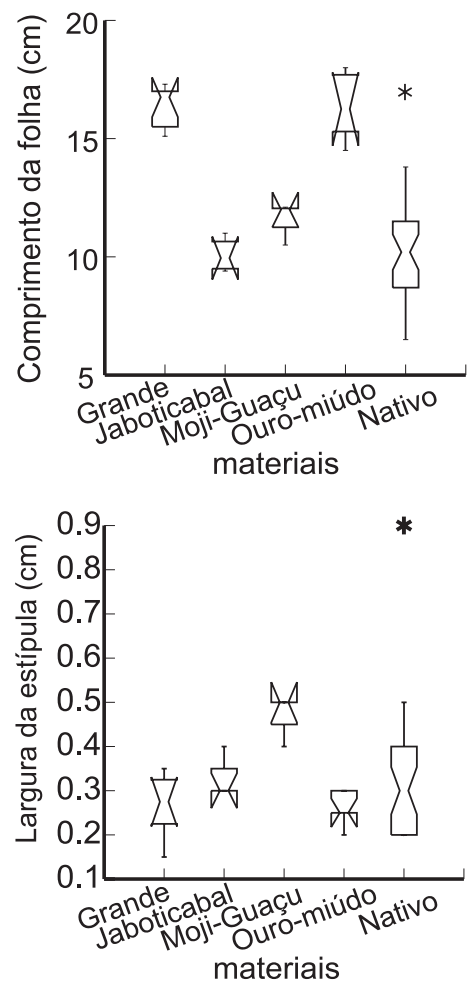

b

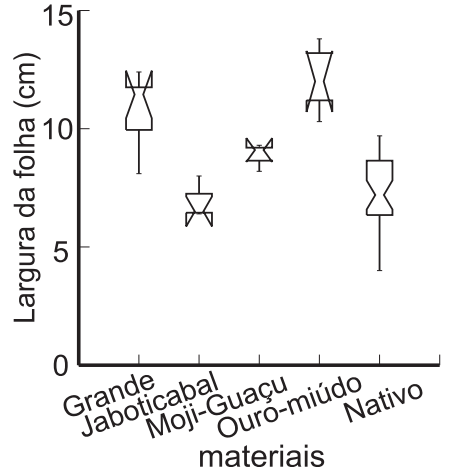

e

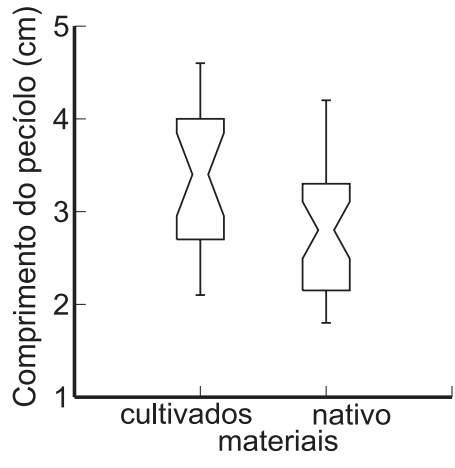

c

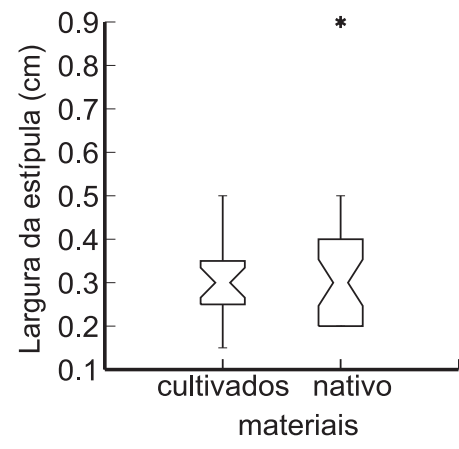

f

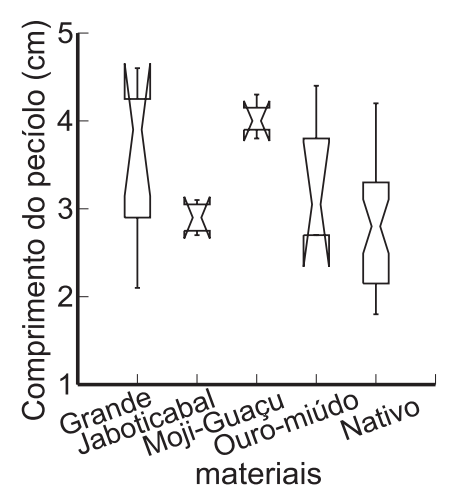

FIGURA 2 - Comparação do comprimento (a) e largura da folha (b), largura da estípula (c-d) e o comprimento do pecíolo (e-f) de $P$. alata entre diferentes acessos, em conjunto e individualizados, cultivados em Monte Alegre do Sul e nativos do Estado de São Paulo. Diferenças significativas se estreitamento no polígono não sobrepostos.

tas mais vigorosas pode levar a um aumento da largura da folha, que pode vir a ficar maior, no futuro.

\section{CONCLUSÕES}

1) Os acessos 'Mogi-Guaçu' e 'Grande' foram superiores aos demais nas características agronômicas e na fertilidade dos grãos de pólen, podendo vir a servir de base para a obtenção de clones selecionados para produtividade e qualidade de frutos.

2) Há necessidade de selecionar plantas com maior tolerância à bacteriose, visando a ampliar o valor comercial das plantas selecionadas.

3) Não houve variação do cariótipo entre os indivíduos da espécie Passiflora alata, independentemente da origem do acesso.

4) As plantas cultivadas apresentam estruturas morfológicas maiores que as nativas.

\section{AGRADECIMENTOS}

Aos funcionários de apoio Antônia Martins Ferreira, José Luiz Hernandes, Maria das Graças dos Santos Lima, Onivaldo Camargo e Valdemir Álvares, pela colaboração no desenvolvimento deste trabalho.

\section{REFERÊNCIASBIBLIOGRÁFICAS}

ALEXANDER, M. P. A Versatile stain for polle fungi, yeast and bactéria. Stain Tecnology Baltimore, v. 55; p.13-18, 1980.

BERNACCI, L.C.; MELETTI, L.M.M.; SOARES-SCOTT, M.D. Maracujá-doce: o autor, a obra e a data da publicação de Passiflora alata (Passifloraceae). Revista Brasileira Fruticultura, Jaboticabal, v. 25, n. 2. 2003. (no prelo).

BERNACCI, L.C.; VITTA, F.A.; BAKKER, Y.V. Passiflora. In WANDERLEY, M.GL.,

SHEPPERD, G.J.; GIULIETTI, A.M. Flora Fanerogâmica do Estado de São Paulo. São Paulo: HUCITEC, v. 3., 2002. (no prelo).

CERVI, A.C. Passifloraceae do Brasil: estudo do gênero Passiflora L. subgênero Passiflora. FontQueria, Madrid, v. 45, p.1-92, 1997.

KILLIP, E.P. The American species of Passifloraceae. Chicago: Field Museum of Natural History (Botanical Series 49), 613p. 1938.
LEVAN, A.,FREDGA, K., SANDEBERG, A.A. Nomenclature for centromeric position on chromosomes. Hereditas, Lund, v 52, p. 201-220. 1964.

McGILL, R., TUKEY, J.W.; LARSEN, W.A. Variations of box plots. The American Statistician, Alexandria, v. 32, p.12-16. 1978.

MELETTI, L.M.M; MAIA, M.L. Maracujá: produção e comercialização. Boletim Técnico Instituto Agronômico Estado de São Paulo, Campinas, v. 181, p. 1-62, 1999.

MELETTI, L.M.M.; SOARES-SCOTT, M.D.; BERNACCI, L.C.; PINTOMAGLIO, C.A F.; MARTINS, F.P. Caracterização e seleção agronômica de germoplasma de maracujá (Passiflora spp). In: CONGRESSO BRASILEIRO FRUTICULTURA, 13., 1994, Salvador. Anais... Salvador, BA: SBF, 1994. v.3.p. 821-822.

OLIVEIRA, J. C.; SALOMÃO, T. A.; RUGGIERO, C.;ROSSINI, A. C. Variações observadas em frutos de Passiflora alata Ait. Proceedings of the tropical region -American Society of Horticultural Science, v. 25, p.343-345. 1982.

RUGGIERO, C. Enxertia do maracujazeiro. In: SÃO JOSÉ, A. R.; FERREIRA, F. R.; VAZ, R.L. A cultura do maracujá no Brasil. Jaboticabal: FUNEP, 1991, p. 43-60.

SALOMÃO, T. A.; ANDRADE, V. M. M. Botânica. In: RUGGIERO, C. Maracujá. Legis Summa: Ribeirão Preto: Legis Summa, 1987. p.20-39

SOARES-SCOTT, M.D. Caracterização citogenética de algumas espécies e híbridos inter-específicos de Passiflora. Campinas, 89f. Dissertação (Mestrado em Ciências Biológicas - Área de Biologia Celular) Universidade Estadual de Campinas, Campinas, 1998.

VASCONCELLOS, M. A. S.; CEREDA, E. O cultivo do maracujá-doce. In: SÃO JOSÉ, A.R.. Maracujá: produção e mercado. Vitória da Conquista: DFZ-UESB, 1994. p. 71-83

VASCONCELLOS, M. A. S.; BRANDÃO FILHO, J. U. T.; VIEITES, R. L. Maracujá-doce. In: BRÜCKNER, C. H.; PICANÇO, M.C. Maracujá: tecnologia de produção, pós-colheita, agroindústria e mercado. Porto Alegre: Cinco Continentes, 472p. 2001.

VERAS, M.C.M. Fenologia, produção e caracterização físico-química dos maracujazeiros ácido (Passiflora edulis f. flavicarpa Deg.) e doce (Passiflora alata Dryand) nas condições de cerrado de BrasíliaDF. 1997. 105f. Dissertação (Mestrado em Agronomia - Área de Fitotecnia) Universidade Federal de Lavras, Lavras, 1997. 